\title{
Canopy-scale wavelength and vegetative index sensitivities to cotton growth parameters and nitrogen status
}

\author{
T. B. Raper · J. J. Varco
}

Published online: 11 October 2014

(C) The Author(s) 2014. This article is published with open access at Springerlink.com

\begin{abstract}
Temporal and spatial variability of plant available $\mathrm{N}$ in the humid southeastern region of the United States often results in within-field over- and under- application of this nutrient to cotton. Although ground-based canopy reflectance has the potential to quantify crop $\mathrm{N}$ status in real-time and drive variable rate fertilizer $\mathrm{N}$ applications, currently utilized vegetation indices often fail to correlate strongly with crop $\mathrm{N}$ status. Therefore, the objective of this study was to examine relationships between canopy reflectance across wavelengths and calculated ratios and vegetation indices prior to and at flowering to biomass, leaf tissue $\mathrm{N}$ concentration, aboveground total $\mathrm{N}$ content and lint yield. Data was collected during the third week of flower bud formation and the first week of flowering during the 2008-2010 growing seasons at Mississippi State, MS, USA. Analysis of wavelength sensitivities indicated reflectance near $670 \mathrm{~nm}$ was most highly correlated to plant height, but relatively poorly correlated to lint yield, total plant $\mathrm{N}$ content and leaf $\mathrm{N}$ concentration. The strongest wavelength correlations with leaf $\mathrm{N}$ concentration, lint yield and plant total $\mathrm{N}$ content were noted near $700 \mathrm{~nm}$. Subsequent analysis indicated indices utilizing reflectance in the red edge region correlated more strongly to leaf $\mathrm{N}$ status and total plant $\mathrm{N}$ content when compared to indices relying on reflectance in green or red regions. Comparisons between simple red edge indices and more complex calculations of the red edge inflection point suggested a simplified version of the Canopy Chlorophyll Content Index calculation may provide reasonable reliability for real-time detection of cotton $\mathrm{N}$ status.
\end{abstract}

Approved for publication as Journal Article No. J-12442 of the Mississippi Agricultural Experiment Station, Mississippi State University.

T. B. Raper

Department of Plant Sciences, University of Tennessee, 605 Airways Blvd, Jackson, TN 38301, USA

J. J. Varco $(\bowtie)$

Plant and Soil Sciences Department, Mississippi State University, PO Box 9555, Mississippi State, MS 39762, USA

e-mail: jvarco@pss.msstate.edu; jjv3@msstate.edu 
Keywords Cotton $\cdot$ Tissue $\mathrm{N} \cdot$ Canopy reflectance $\cdot$ Vegetation index $\cdot$ Fertilizer $\mathrm{N}$

\section{Introduction}

In-season determination of cotton (Gossypium hirsutum L.) $\mathrm{N}$ status is useful for helping producers adjust fertilizer $\mathrm{N}$ application rates across spatially variable fields in an effort to reduce instances of over- or under- application. Crop sensors in close proximity to the plant canopy have the potential to provide this information in a timely manner, while simultaneously providing input information for variable $\mathrm{N}$ fertilization (Zhao et al. 2005). The normalized difference vegetation index (NDVI) is commonly employed with a couple of commercially available sensors as well as in aerial- and satellite-based imaging platforms. Although this index often correlates strongly to the $\mathrm{N}$ status of wheat (Triticum aestivum L.) as well as some other crops, this relationship as measured with active ground-based sensors for cotton has been observed as weak (Raper et al. 2013; Bronson et al. 2005; Li et al. 2001; Plant et al. 2000). This has led to investigation of other regions in cotton's spectral reflectance signature for vegetative index testing and development to more accurately define targeted biophysical indicators. One region which has shown strong correlations to cotton $\mathrm{N}$ status at the leaf reflectance scale is the red edge, or the region immediately between maximum absorption of red and the near-infrared reflection (Fridgen and Varco 2004; Buscaglia and Varco, 2002).

The red edge is considered one of the most sensitive regions to changes in chlorophyll content. Gates et al. (1965) noted a systematic shift in the red edge to longer wavelengths as chlorophyll content increased for reflectance measurements of several white oak (Quercus alba L.) leaves of varying age. Research on peppers (Capsicum annuum L.) indicated significant shifts to longer wavelengths as chlorophyll content increased and shifts to shorter wavelengths were associated with decreases in chlorophyll content or an increase in $\mathrm{N}$ deficiency. Horler et al. (1983a) reported that the position of the red edge was unaffected by simulated ground cover change, but increases in leaf layers did shift the red edge to longer wavelengths. Further research suggested that the ability of the red edge shift to determine chlorophyll status and Leaf Area Index (LAI) independent from ground cover percentage allows it to be an option for early stress detection (Horler et al. 1983b). More recent research by Schlemmer et al. (2005) noted strong relationships between the red edge position and chlorophyll content in corn (Zea mays L.).

Although the red edge shift has been difficult to measure from coarse data, its well established sensitivity to chlorophyll concentration has prompted the development of various methods and indices to quantify the shift. These methods differ, as red edge reflectance indices/ratios typically range from 0 to 1 , while red edge position indices identify mathematically the wavelength of the red edge inflection point.

Studies examining a variety of plants and stress factors have found simple ratio indices of $R_{695} / R_{420}$ and $R_{695} / R_{760}$ to be the most strongly affected by plant stress (Carter, 1994). Recent work inspecting the first derivative of the canopy reflectance signature at $735 \mathrm{~nm}$ $\left(\mathrm{dR} /\left.\mathrm{d} \lambda\right|_{735}\right)$ in rice (Oryza sativa $\mathrm{L}$.) indicated a linear relationship between $\mathrm{dR} / \mathrm{d} \lambda \mathrm{I}_{735}$ and leaf $\mathrm{N}$ concentration at panicle formation (Lee et al. 2008). In comparison to NDVI, the simple ratio vegetation index (SRVI) and several others also resulted in the $\mathrm{dR} / \mathrm{d} \lambda \mathrm{I}_{735}$ providing a better fit to leaf $\mathrm{N}$ accumulation per unit ground area (Lee et al. 2008). Research by Hunt et al. (2011) also noted better relationships between wheat chlorophyll 
content and indices utilizing reflectance in the red edge region than indices using standard broad-band reflectance data.

Studies by Cammarano et al. (2011) and Eitel et al. (2010) noted strong relationships with plant N parameters and CCCI. First described by Barnes et al. (2000), the traditional calculation of CCCI utilizes NDVI as a measure of percent canopy ground cover on which to normalize the normalized difference red edge (NDRE). In order to calculate CCCI, the authors suggested minimum and maximum lines, representing severely stressed and optimum conditions, should be empirically drawn after data collection as upper and lower bounds to observed data.

Other research by El-Shikha et al. (2008) examined CCCI in relation to cotton $\mathrm{N}$ and water stress and concluded CCCI could determine cotton $\mathrm{N}$ status independently from biomass so long as $30 \%$ ground cover was present and irrigation was properly managed. Limited success in predicting wheat $\mathrm{N}$ status and chlorophyll $a$ content from CCCI data was noted by Fitzgerald et al. (2006), but Rodriguez et al. (2006) noted strong correlations between CCCI and wheat $\mathrm{N}$ status independent of water stress and crop/plant density. Other combined indices which have shown potential include the Transformed Chlorophyll Absorption in Reflectance Index divided by the Optimized Soil-adjusted Vegetation Index (Haboudane et al. 2002) and the Modified Chlorophyll Absorption in Reflectance Index divided by the Second Modified Triangular Vegetation Index (Eitel et al. 2008, 2007; Hunt et al. 2011).

Still, changes in reflectance magnitude for a given wavelength within the red edge region have been suggested to be inferior to relationships with the actual wavelength shift measurements. Horler et al. (1983b) reported that one disadvantage to measuring only reflectance within the red edge or using a ratio of several reflectance wavelengths is the failure to isolate the spectral properties of the vegetation from soil reflectance, irradiance, directional reflectance dependence or atmospheric transmittance.

A proposed method to improve measurement accuracy of the red edge shift is the calculation of the red edge inflection point (REIP), or the exact point where the red edge curve shifts from concave up to convex up (Bonham-Carter, 1988). This point is also referred to as the maximum inflection point of the red edge and extensive research has been conducted in forestry on the point's movement as influenced by plant stress or damage (Hoque and Hutzler, 1992; Cibula and Carter, 1992; Curran et al. 1995). Influences of soil reflectance, irradiance, directional reflectance dependence and atmospheric transmittance are generally considered to be minimal with the calculation of a waveform analysis, so the REIP is at least theoretically less sensitive to inconsistencies typically associated with reflectance magnitude or ratios (Horler et al. 1983b).

Concerning relatively dense multi-spectral or hyperspectral datasets, this point is generally determined by calculating the first derivative of the reflectance signature curve and then applying a curve fitting method to determine the peak. Due to a limited number of wavelengths available to perform the calculation with many sensors, a substantial amount of research has focused on the mathematical determination of the REIP from such data. Both linear and non-linear Inverted Gaussian Models were examined by Bonham-Carter (1988) to determine REIP and due to subtle changes in the red edge corresponding to plant stress, the non-linear full model was concluded as superior. Further research also supported these conclusions (Miller et al. 1990). Similarly, Dawson and Curran (1998) examined a linear and Inverse Gaussian method, but also used a new method based upon a Lagrangian interpolation to determine REIP. The authors concluded flexibility to unequally-spaced wavelengths and the lack of required a priori knowledge of the investigated spectrum made the new Lagrangian interpolation a simpler substitute for the complex inverse Gaussian 
method (Dawson and Curran, 1998). Other research examining a four-point interpolation, polynomial fitting, the Lagrangian Technique and the Inverted-Gaussian Modeling approaches to calculate the REIP suggested that for moderately coarse to coarse data, the four point interpolation or polynomial fitting methods were most practical (Pu et al. 2003).

Still, it is important to note that several studies have reported red edge shifts for several plant species to be sensitive to a variety of plant stresses, and not exclusively to $\mathrm{N}$ stress. Masoni et al. (1996) examined the leaf reflectance properties of barley (Hordeum vulgare L.), wheat, corn and sunflower (Helianthus annuus L.) deficient in Fe, S, Mg and Mn. Results suggested that nutrient deficiencies in each crop resulted in a red edge shift and the magnitude was relative to crop and deficiency severity. Although each nutrient resulted in a similar shift, a priori knowledge of a specific deficiency could make determination of stress magnitude plausible (Masoni et al. 1996). Carter (1994) found ratios involving red edge reflectance to be sensitive to multiple stresses across several different plant species. One index utilizing red edge reflectance $\left(\mathrm{R}_{710} / \mathrm{R}_{760}\right)$ actually displayed sensitivity to all stress agents studied (Carter 1994). Pigment concentrations in the leaf have also been shown to impact red edge position. Although at low amaranthin concentrations in Amaranthus spp. leaves, the relationship between red edge and chlorophyll concentration is almost linear, at high amaranthin concentrations, the red edge shifts to longer wavelengths regardless of chlorophyll concentrations (Curran et al. 1991).

Other studies have defined shifts of the red edge to be sensitive to cultural and physiological parameters. Broge and Leblanc (2000) examined various types of vegetation indices, parameterizations of the red edge and indices based on spectral continuum measures against a simulated data reflectance model. The most accurate estimation of REIP researched was the Lagrangian interpolation, but even the Lagrangian REIP only predicted canopy chlorophyll density (CCD) at high vegetation densities due to very high sensitivity of the analysis to canopy, background and atmospheric parameters. Furthermore, the red edge predictors were not necessarily better predictors of leaf area index or CCD than other more traditional VIs studied (Broge and Leblanc, 2000). Further research examining N treatments in field scale wheat production by Broge and Mortensen (2002) led the authors to conclude that the Lagrangian REIP and the 2nd soil-adjusted vegetation index (SAVI2) were the two best predictors of CCD researched. The authors concluded from these results that red edge VIs do have potential to improve CCD prediction.

Even more concerning are studies suggesting relationships between $\mathrm{N}$ stress and REIP deteriorate at the canopy or scene scale. Studies examining varying levels of $\mathrm{N}$ applied to sugar beet (Beta vulgaris) resulted in poor relationships between leaf reflectance REIP and canopy reflectance REIP (Demetriades-Shah et al. 1990). Similar results were found in research examining the relationships between chlorophyll content with leaf and canopy reflectance in slash pine (Pinus elliottii Engelm.). At the leaf or branch scale, correlations between chlorophyll content and REIP were strong (Curran et al. 1995), but no relationships were noted at the canopy scale possibly due to the influence of the understory or forest floor (Curran et al. 1990). Although analysis of wavelengths from 438 to $884 \mathrm{~nm}$ resulted in strong correlations between the red edge region and green biomass, and LAI and chlorophyll density, the red edge has on occasion been shown to not correlate as strongly to leaf $\mathrm{N}$ concentration or chlorophyll content as the blue region (Hansen and Schjoerring, 2003).

Therefore, the objectives of this study were to examine sensitivities of various wavelengths, published ratios and indices derived from passive cotton canopy reflectance to changes in biomass and $\mathrm{N}$ status indicators, and to identify indices most compatible to current $\mathrm{N}$ fertilization management practices (e.g., early deficiency detection, insensitivity 
to changes in plant height and a consistent range of values during the fertilizer application window across years).

\section{Materials and methods}

A 0.75 ha trial was conducted at the W.B. Andrews Agricultural Systems Research Center $\left(33^{\circ} 28^{\prime} 13.5^{\prime \prime} \mathrm{N}, 88^{\circ} 45^{\prime} 48.0^{\prime \prime} \mathrm{W}\right)$ at Mississippi State, MS, USA from 2008 through 2010. Each of 16 plots consisted of 12 rows at a spacing of $0.965 \mathrm{~m}$ and a length of $38.1 \mathrm{~m}$. Four sub-location points were geo-referenced in each plot with two points located on both rows 3 and 10 (Fig. 1). Canopy sensing and plant sampling were conducted within $9 \mathrm{~m}$ of sublocation points. This reduced the influence of non-sampled material on reflectance averages in an effort to obtain better insight into reflectance sensitivities.

Treatments consisted of a 50/50 split application of urea-ammonium nitrate (UAN $32 \%$ ) fertilizer solution for a total $\mathrm{N}$ application of $0,45,90$ and $135 \mathrm{~kg} \mathrm{~N}^{-1}$ during the growing season. Each fertilizer $\mathrm{N}$ rate treatment was replicated four times and treatments were arranged in a randomized complete block design. Nitrogen application rates were chosen to provide a range of available $\mathrm{N}$ from deficient through, and exceeding, the agronomic optimum. The first application was made shortly after planting and the sidedress application was made at early flower bud initiation. Plant measurements included total $\mathrm{N}$ analysis of the uppermost fully expanded leaf on the main stem, plant height, total plant $\mathrm{N}$ content at early boll opening and lint yield following harvest. Total $\mathrm{N}$ on plant materials was determined using a Carlo/Erba N/C 1500 automated dry combustion analyzer (Carlo/Erba, Milan, Italy). Detailed descriptions of cultural practices, sampling procedures and other general trial information can be found in Raper et al. (2013).

A particular emphasis was placed on determining leaf $\mathrm{N}$ status during a period in which a yield-impacting fertilizer $\mathrm{N}$ application could be conducted. Subsequently, analyzed data included reflectance collected from the third week of flower bud formation to the first week of flowering. Although generally considered to be the latter half of the side dress $\mathrm{N}$ fertilization window, this period was selected to allow time for slight $\mathrm{N}$ stress symptoms to develop and therefore, maximize relationships between reflectance and plant parameters.

Reflectance values were acquired on clear sunny days between 10 a.m. and 12 p.m. using a tractor mounted Yara N Sensor (Yara International ASA, Oslo, Norway) with the viewing lenses $1.93 \mathrm{~m}$ above the ground. The Yara N Sensor is a passive multi-spectral scanner consisting of two diode array spectrometers. The unit was programmed to record reflectance at 450, 500, 550, 570, 600, 620, 640, 650, 660, 670, 680, 700, 710, 720, 740, $760,780,800,840$ and $850 \mathrm{~nm}$ at an acquisition interval of one second. The second spectrometer is connected to an irradiance detector which points skyward and is used to correct for variations in light intensity. Additional specifications and description of the sensor can be found in Raper et al. (2013).

Recorded wavelengths were used to calculate 13 ratios and indices with known sensitivity to various indicators of plant growth and chlorophyll or greenness and are listed in Table 1. In preliminary work, these indices were found to be the most consistent in their response to $\mathrm{N}$ across biophysical measurements used in this study. For this study, indices requiring reflectance in the green, red, red edge or NIR region were calculated with collected wavelengths of 550, 650, 720 and $840 \mathrm{~nm}$, respectively (Table 1). These wavelengths varied slightly in comparison to published values due to differences in sensor technology. The Gaussian REIP was calculated using reflectance at 680, 710, 720 and $760 \mathrm{~nm}$. The first derivative of this curve was calculated and then a non-linear Gaussian 
Fig. 1 Image displaying reflectance measurement points (white and blue dots), plant sampling points (green dots), and applied buffer constraints (yellow circles) across field trial at one sampling date. Blue dots represent reflectance measurements which were excluded from analysis. White dots represent measurements which corresponded to plant sampling points and were therefore included in the analysis. Reproduced from Raper et al. (2013) (Color figure online)

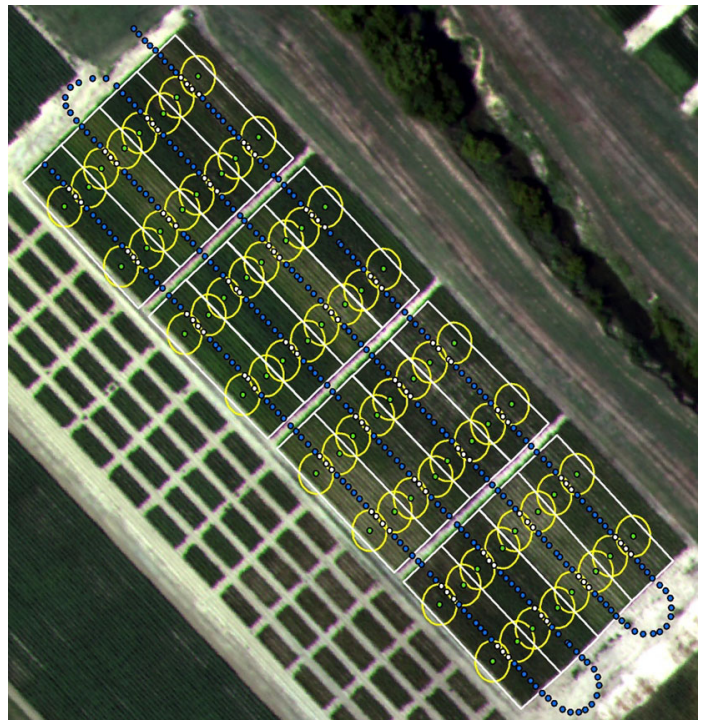

3-Parameter peak equation was fit to the data using SigmaPlot, Version 11 (Systat Software, Inc., San Jose, CA, USA).

Statistical analysis was conducted using JMP, Version 10 (SAS Institute Inc., Cary, NC, USA). Pearson correlations were examined between wavelengths and indices and plant height, leaf $\mathrm{N}$, total $\mathrm{N}$, lint yield and $\mathrm{N}$ rate treatment. Relationships between indices were also modeled in order to provide insight on individual index characteristics.

\section{Results and discussion}

Plant response to fertilizer $\mathrm{N}$ rate

Lint yield response to an increase in fertilizer $\mathrm{N}$ rate was quadratic in all 3 years, with yields generally increasing up to $90 \mathrm{~kg} \mathrm{~N} / \mathrm{ha}$ before decreasing at the greatest $\mathrm{N}$ rate (Raper et al. 2013). Nitrogen rates induced differences in plant height, leaf $\mathrm{N}$ and total $\mathrm{N}$ content each year of the study. Further details of these responses are described in Raper et al. (2013). Due to varying lint yield ranges between years, \% Relative Yield (Relative Yield $=($ Observed Plot Yield/Maximum Yearly Plot Yield) X 100) was calculated and used in the analyses to normalize across years.

Early season wavelength analysis

Average correlations between wavelengths and parameters of interest are displayed in Table 2. Across wavelengths, absolute reflectance was most strongly correlated to plant height $(\mathrm{r}=0.67)$, followed by total $\mathrm{N}$ content $(\mathrm{r}=0.55)$. It is also appropriate to note that correlations were calculated with absolute, non-normalized data from two sampling dates per year. In order to qualitatively compare sensitivities, reflectance at all 20 wavelengths for each of the two sensing dates were ranked based on their Pearson correlation to each 
Table 1 Vegetation indices and ratios calculated from spectral reflectance collected by the Yara N Sensor

\begin{tabular}{|c|c|c|c|}
\hline $\begin{array}{l}\text { Vegetation } \\
\text { Indice }\end{array}$ & Name & Formula & Reference \\
\hline GRVI & Green RVI & $\mathrm{R}_{\mathrm{NIR}} / \mathrm{R}_{\text {GREEN }}$ & Tucker (1979) \\
\hline NDVI & $\begin{array}{l}\text { Normalized difference vegetation } \\
\text { index }\end{array}$ & $\begin{array}{l}\left(\mathrm{R}_{\mathrm{NIR}}-\mathrm{R}_{\mathrm{RED}}\right) / \\
\quad\left(\mathrm{R}_{\mathrm{NIR}}+\mathrm{R}_{\mathrm{RED}}\right)\end{array}$ & Rouse et al. (1973) \\
\hline GNDVI & Green NDVI & $\begin{array}{l}\left(\mathrm{R}_{\mathrm{NIR}}-\mathrm{R}_{\mathrm{GREEN}}\right) / \\
\quad\left(\mathrm{R}_{\mathrm{NIR}}+\mathrm{R}_{\mathrm{GREEN}}\right)\end{array}$ & Gitelson et al. (1996) \\
\hline NDRE & $\begin{array}{l}\text { Normalized difference red edge } \\
\text { index }\end{array}$ & $\begin{array}{l}\left(\mathrm{R}_{\mathrm{NIR}}-\mathrm{R}_{\mathrm{EDGE}}\right) / \\
\quad\left(\mathrm{R}_{\mathrm{NIR}}+\mathrm{R}_{\mathrm{EDGE}}\right)\end{array}$ & $\begin{array}{l}\text { Gitelson \& Merzlyak } \\
\text { (1994) }\end{array}$ \\
\hline $\mathrm{R}_{750} / \mathrm{R}_{550}$ & R750/R550 & $\mathrm{R}_{750}^{\mathrm{a}} / \mathrm{R}_{550}$ & $\begin{array}{l}\text { Gitelson \& Merzlyak } \\
\text { (1997) }\end{array}$ \\
\hline $\mathrm{R}_{750} / \mathrm{R}_{700}$ & R750/R700 & $\mathrm{R}_{750}^{\mathrm{a}} / \mathrm{R}_{700}$ & $\begin{array}{l}\text { Gitelson and Merzlyak } \\
\text { (1997) }\end{array}$ \\
\hline $\mathrm{R}_{780} / \mathrm{R}_{700}$ & R780/R700 & $\mathrm{R}_{780} / \mathrm{R}_{700}$ & $\begin{array}{l}\text { Mistele and } \\
\text { Schmidhalter (2010) }\end{array}$ \\
\hline $\mathrm{R}_{780} / \mathrm{R}_{740}$ & R780/R740 & $\mathrm{R}_{780} / \mathrm{R}_{740}$ & $\begin{array}{l}\text { Mistele and } \\
\text { Schmidhalter (2010) }\end{array}$ \\
\hline LREI & Linear red edge index & $\begin{array}{c}700+40\left[\left(\mathrm{R}_{670}+\mathrm{R}_{780}\right) /\right. \\
\left.2-\mathrm{R}_{700}\right] /\left(\mathrm{R}_{740}-\mathrm{R}_{700}\right)\end{array}$ & Guyot et al. (1992) \\
\hline REIP & $\begin{array}{l}\text { Gaussian-calculated red edge } \\
\text { inflection point }\end{array}$ & Described in text & \\
\hline \multicolumn{4}{|c|}{ COMBINED INDICE } \\
\hline SCCCI & $\begin{array}{l}\text { Simplified canopy chlorophyll } \\
\text { content index }\end{array}$ & NDRE/NDVI & Barnes et al. (2000) \\
\hline
\end{tabular}

a $\mathrm{R} 750$ replaced with both $\mathrm{R} 740$ and $\mathrm{R} 760$

plant measurement, with the highest ranking (i.e. 1) corresponding to the strongest absolute correlation relative to the other 19 wavelengths. Rankings from the third week of flower bud formation and first week of flowering in all three years are displayed in Fig. 2. As expected, trends in wavelength sensitivity between total $\mathrm{N}$ content and leaf $\mathrm{N}$ concentration were very similar. In all three years of this study, absolute reflectance was most frequently the strongest correlated at wavelengths of 700 and $710 \mathrm{~nm}$ to biophysical measurements. Strong correlations to $\mathrm{N}$ rate, leaf $\mathrm{N}$ concentration and total $\mathrm{N}$ content were also observed with the green and far-green wavelengths $(550$ and $570 \mathrm{~nm})$. In contrast, wavelengths most sensitive to changes in plant height were located in the red or far-red wavelengths between 650 and $680 \mathrm{~nm}$. Lint yield response was similar to that of total $\mathrm{N}$ content, with the red edge and green regions resulting in the most frequent, strongest correlations. The large error bars associated with rank of reflectance in the $710 \mathrm{~nm}$ region are due to the "shifting" of the red edge position, and therefore volatility of absolute reflectance at this position.

These results support findings of Zhao et al. (2005), Fridgen and Varco (2004) and Buscaglia and Varco (2002). Although the aforementioned studies examined leaf reflectance, they concluded that reflectance in the red edge $(700-720 \mathrm{~nm})$ region to be the most sensitive to fertilizer $\mathrm{N}$ rate treatments and chlorophyll content. Zhao et al. (2005) and Buscaglia and Varco (2002) similarly found cotton leaf reflectance in the green $(\sim 550 \mathrm{~nm})$ region to be sensitive to fertilizer $\mathrm{N}$ rate treatment and chlorophyll content. These results also support findings in several other crops; strong separation between $\mathrm{N}$ 
Table 2 Average of Pearson correlations (r) calculated from 2008 through 2010 for the third week of flower bud formation and early flowering

\begin{tabular}{lcccc}
\hline Pearson correlation $(\mathrm{r})$ & \multicolumn{5}{l}{} \\
\hline Wavelength $(\mathrm{nm})$ & Total N content & Leaf N concentration & Plant height & Relative yield \\
\hline 450 & -0.568 & -0.329 & -0.728 & -0.240 \\
500 & -0.609 & -0.370 & -0.746 & -0.266 \\
550 & -0.753 & -0.546 & -0.670 & -0.318 \\
570 & -0.750 & -0.535 & -0.711 & -0.329 \\
600 & -0.721 & -0.499 & -0.750 & -0.331 \\
620 & -0.695 & -0.470 & -0.762 & -0.323 \\
640 & -0.675 & -0.448 & -0.769 & -0.313 \\
650 & -0.653 & -0.423 & -0.773 & -0.300 \\
660 & -0.627 & -0.395 & -0.776 & -0.283 \\
670 & -0.605 & -0.371 & -0.776 & -0.268 \\
680 & -0.606 & -0.372 & -0.776 & -0.268 \\
700 & -0.763 & -0.560 & -0.721 & -0.359 \\
710 & -0.774 & -0.607 & -0.586 & -0.345 \\
720 & -0.577 & -0.500 & -0.191 & -0.240 \\
740 & 0.092 & 0.059 & 0.514 & 0.029 \\
760 & 0.272 & 0.227 & 0.628 & 0.117 \\
780 & 0.301 & 0.255 & 0.640 & 0.129 \\
800 & 0.304 & 0.258 & 0.639 & 0.125 \\
840 & 0.299 & 0.253 & 0.626 & 0.112 \\
850 & 0.299 & 0.253 & 0.623 & 0.110 \\
Average across wavelengths & 0.547 & 0.387 & 0.670 & 0.240 \\
\hline & & & &
\end{tabular}

rates as determined by canopy and leaf reflectance at $550 \mathrm{~nm}$ has been noted in corn (Blackmer et al. 1996; Shanahan et al. 2001) and several other crops (Thomas and Gausman, 1977; Gitelson et al. 1996).

Additionally, these results also support the findings of Tarpley et al. (2000) and Read et al. (2002). From their studies on leaf and canopy reflectance, the authors concluded that ratios which included reflectance in the red edge region led to the greatest correlations with chlorophyll content and leaf N concentration. Read et al. (2002) also noted sensitive ratios included reflectance in the very near blue region, and Tarpley et al. (2000) noted sensitive ratios also included reflectance in the very near infrared region (755-920 and $1000 \mathrm{~nm}$ ); however, results from this study were limited to $450-850 \mathrm{~nm}$, so neither reflectance at 415 or $860-1000 \mathrm{~nm}$ were examined.

Early season index analysis

Pearson correlations of each index to parameters of interest were calculated from a pooled dataset containing all collected wavelengths from the third week of flower bud formation and first week of flower in all 3 years (Table 3). Correlations of NDVI and GNDVI with plant height were substantially stronger than red edge based indices (Table 3). In contrast, correlations of red edge based indices with leaf $\mathrm{N}$ status were much stronger than for 


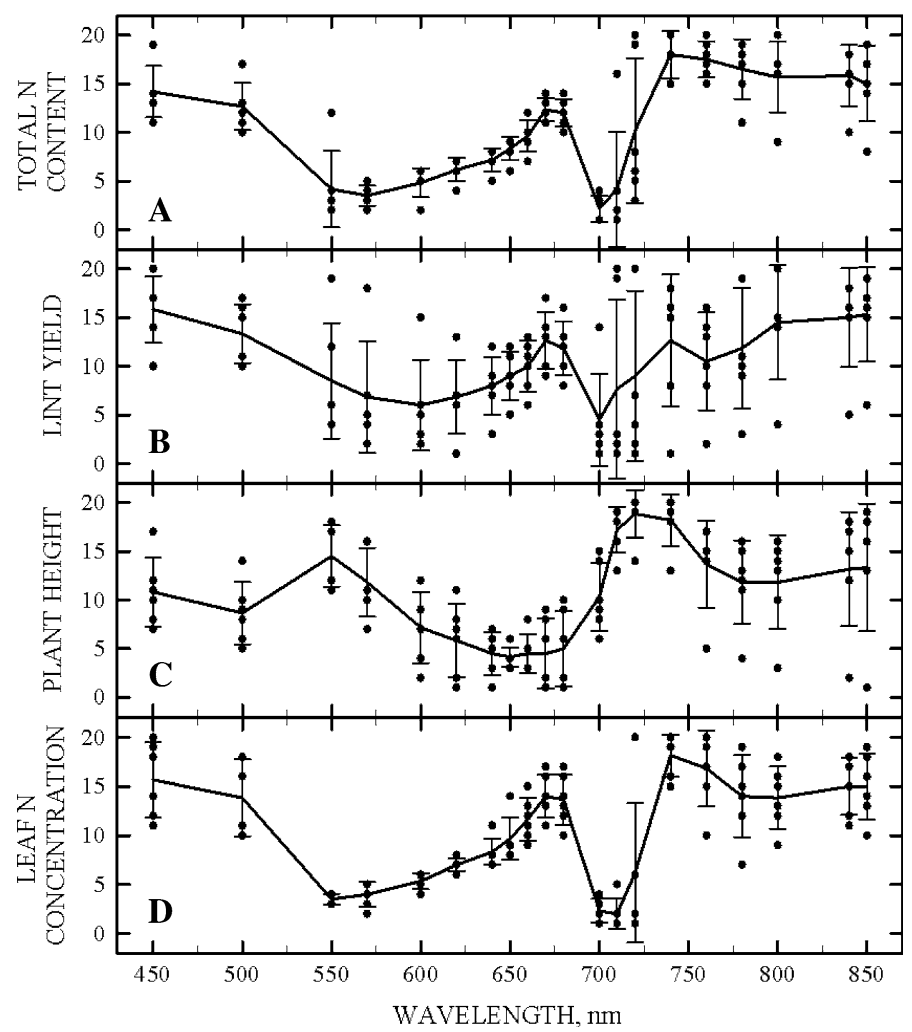

Fig. 2 Ranking of wavelengths for the third week of flower bud formation and first week of flowering in all 3 years, where low numbers represent greater Pearson correlations of reflectance to plant measurements at a specified wavelength relative to all other wavelengths. Error bars represent one SD from the mean. Line represents average of six observations (2 sampling times/year X 3 y). Points represent values of individual rankings

correlations of NDVI and GNDVI. Correlations of red edge based indices with total N content were also stronger than for correlations of NDVI and GNDVI. Particularly unique indices were selected for further analysis. These included NDVI, GNDVI, LREI, CCCI and REIP. Visual representation of these relationships is shown in Fig. 3. Relationships between NDVI and GNDVI and plant height were much stronger than relationships between red edge indices and plant height. In contrast, relationships between red edge indices and plant $\mathrm{N}$ measurements were much stronger than coefficients of determination between NDVI and GNDVI and plant $\mathrm{N}$ measurements.

It is noteworthy to point out that the original CCCI, as defined by Barnes et al. (2000) and utilized by Cammarano et al. (2011), El-Shikha et al. (2008), and Rodriguez et al. (2006), differs from the method of CCCI calculation used in the present study. In contrast to the original CCCI, a simplified version utilized in this study considers maximum and minimum threshold slopes to be equal to 1 and 0 , respectively; and therefore, requires no post-acquisition analysis. Although an empirical threshold selection increases the slope of the regression line, it fails to increase the relative separation of data points and therefore does not increase coefficients of determination between reflectance and variables of 
Table 3 Pearson correlation (r) between indices and parameters of interest during the period from third week of flower bud formation to first flowering

\begin{tabular}{lllll}
\hline Pearson correlation $(\mathrm{r})$ & & & \\
\hline Index & Total N content & Leaf N concentration & Plant height & Relative yield \\
\hline GRVI & 0.538 & 0.348 & 0.859 & 0.270 \\
NDVI & 0.398 & 0.096 & 0.842 & 0.200 \\
GNDVI & 0.544 & 0.280 & 0.831 & 0.261 \\
NDRE & 0.617 & 0.385 & 0.798 & 0.314 \\
$\mathrm{R}_{740} / \mathrm{R}_{700}$ & 0.500 & 0.276 & 0.865 & 0.281 \\
$\mathrm{R}_{760} / \mathrm{R}_{700}$ & 0.512 & 0.305 & 0.863 & 0.286 \\
$\mathrm{R}_{780} / \mathrm{R}_{700}$ & 0.518 & 0.315 & 0.861 & 0.286 \\
$\mathrm{R}_{780} / \mathrm{R}_{740}$ & 0.666 & 0.600 & 0.720 & 0.318 \\
$\mathrm{R}_{740} / \mathrm{R}_{550}$ & 0.508 & 0.286 & 0.867 & 0.268 \\
$\mathrm{R}_{760} / \mathrm{R}_{550}$ & 0.522 & 0.318 & 0.865 & 0.276 \\
LREI $_{\text {REIP }}$ & 0.772 & 0.724 & 0.521 & 0.397 \\
SCCCI & 0.773 & 0.680 & 0.608 & 0.423 \\
\end{tabular}

interest (data not shown). The results suggest a simplified version of the original CCCI, also used by Eitel et al. (2010), better fit requirements of on-the-go variable rate $\mathrm{N}$ fertilization in real-time. Also, wavelengths of 650,720 and 840 were used whereas, Barnes et al. (2000) used 670, 720 and 790. Thus, it will be referred to herein as the Simplified CCCI (SCCCI).

Results also suggest LREI correlates strongly to the more complex Gaussian REIP (Fig. 4). The LREI only requires reflectance from four wavelengths in the red, red edge and NIR regions and is easier to calculate, as it does not require derivative analysis. The Gaussian REIP requires the same number of reflectance bands but, in addition, requires derivative analysis and the implementation of a Gaussian peak equation to define REIP. Previous research has concluded that the LREI method may overestimate REIP by $10 \mathrm{~nm}$, but maintains a very high coefficient of determination which is not statistically different from either Gaussian or Lagrangian methods of REIP derivation (Dawson and Curran, 1998). Results from this study contrast the over-estimation by LREI; REIP was on average $1.5 \mathrm{~nm}$ greater than LREI. This may be a function of canopy architecture differences between row-crop agriculture and forest landscapes. Further research by Mistele and Schmidhalter (2008) noted an average coefficient of determination of 0.95 across three growing seasons between Guyot's linear REIP (Guyot et al. 1992) and an indicator of crop $\mathrm{N}$ status. Clevers et al. (2000) concluded that even though the "linear method" REIP failed to correlate strongly with the maximum of the first derivative, due to its limited number of required bands and its very robust nature, the linear REIP method may be more useful for practical applications than other more complex REIP methods. Since relative REIP and not actual REIP is of interest in this situation, the much simpler, more rapid "linear method" may be preferred for an on-the-go objective.

The sensitivity equivalent (SEq) of each VI to plant measurements was determined by dividing the slope for each linear response trend shown in Fig. 3 by its corresponding Root mean square error (RMSE) (Solari et al. 2008) as interpreted from Vina and Gitelson (2005). Values are shown in Table 4. For total plant $\mathrm{N}$ at early boll opening, SCCCI was 


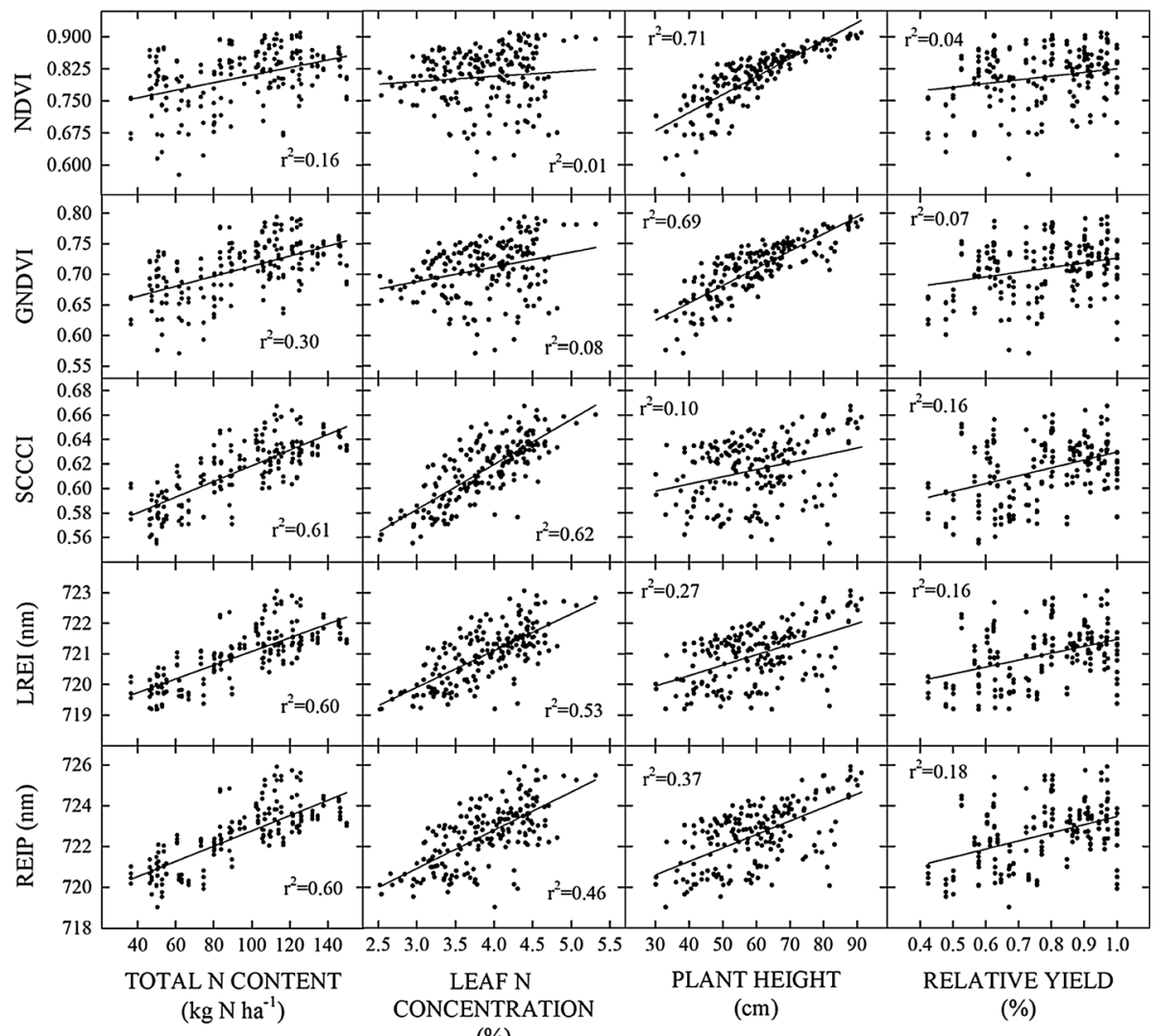

Fig. 3 Average response across the third week of flower bud formation and first week of flowering (latter half of side dress $\mathrm{N}$ fertilization period) in several selected indices to changes in selected cotton growth parameters

the most sensitive followed by LREI and REIP. For early season leaf tissue N concentration, SCCCI was again the most sensitive followed by LREI and REIP. In contrast, for early season plant height which is an indicator of biomass, NDVI was found to be the most sensitive followed by GNDVI. Although none of the relationships between relative yield and any of the vegetative indices were strongly related (Fig. 3), REIP was the most sensitive followed by SCCCI and LREI. These results offer further support for the use of a VI which includes a red edge component to estimate the $\mathrm{N}$ status of early season cotton.

\section{Conclusions}

Adoption of new indices which are more sensitive to early season cotton leaf $\mathrm{N}$ status are necessary before a producer will be able to benefit greatly from an on-the-go sensor-based variable rate fertilizer $\mathrm{N}$ application. The observed stronger dependency of NDVI and GNDVI on biomass as measured with plant height, calibration or algorithm development utilizing these indices for variable rate $\mathrm{N}$ fertilization will require accounting for the 
Fig. 4 Relationships between LREI and SCCCI with REIP from 2008 through 2010 for the third week of flower bud formation and early flowering

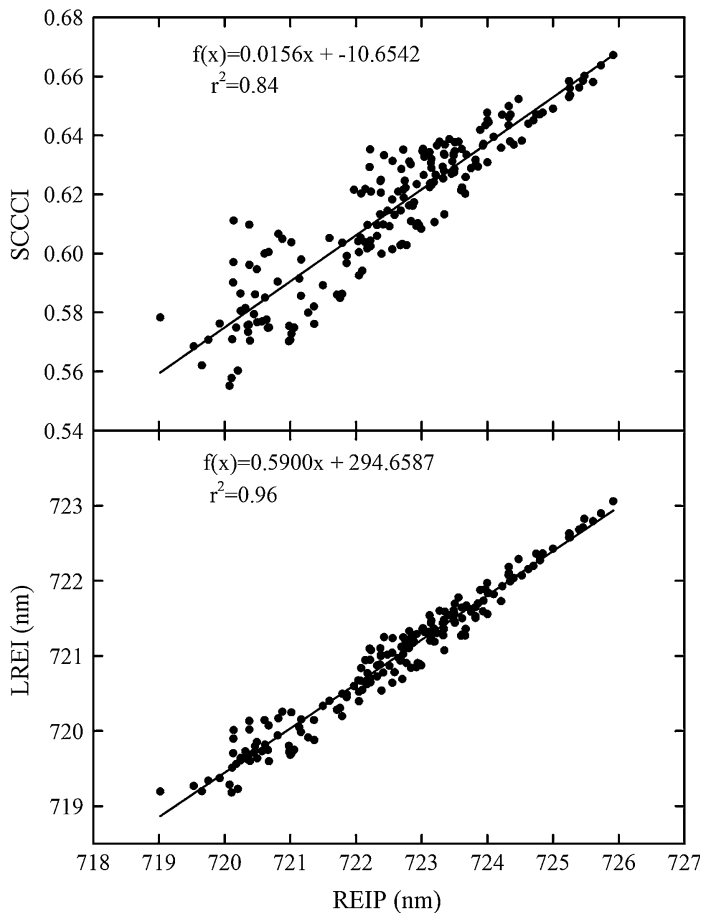

Table 4 Root mean square errors, slopes, and sensitivity equivalents for selected indices

\begin{tabular}{lcccc}
\hline Root mean square error (RMSE) & & & \\
\hline Index & Total N content & Leaf N concentration & Plant height & Relative yield \\
\hline NDVI & 0.0632 & 0.0686 & 0.0371 & 0.0675 \\
GNDVI & 0.0393 & 0.0450 & 0.0260 & 0.0452 \\
SCCCI & 0.0160 & 0.0157 & 0.0241 & 0.0234 \\
LREI & 0.5738 & 0.6224 & 0.7704 & 0.8284 \\
REIP & 0.9522 & 1.1002 & 1.1920 & 1.3598 \\
Slope & & & & 0.0869 \\
NDVI & 0.0009 & 0.0121 & 0.0042 & 0.0768 \\
GNDVI & 0.0008 & 0.0241 & 0.0028 & 0.0644 \\
SCCCI & 0.0006 & 0.0368 & 0.0006 & 2.2555 \\
LREI & 0.0225 & 1.1994 & 0.0341 & 3.9978 \\
REIP & 0.0374 & 1.8731 & 0.0662 & 1.2868 \\
Sensitivity & equivalent $($ SEq) & & & 1.6997 \\
NDVI & 0.0140 & 0.1765 & 0.1134 & 2.7563 \\
GNDVI & 0.0209 & 0.5350 & 0.1086 & 2.7229 \\
SCCCI & 0.0399 & 2.3380 & 0.0243 & 2.9399 \\
LREI & 0.0392 & 1.9272 & 0.0443 & 0.0555 \\
REIP & 0.0393 & 1.7025 & & \\
\end{tabular}


changes in magnitude of these indices with growth progression for a pre-determined fertilizer application window. Due to the relatively lower sensitivity to biomass and greater sensitivity to crop greenness or chlorophyll, red edge indices appear to be more appropriate for use as a crop $\mathrm{N}$ indicator to determine crop demand or needs for fertilizer N. From the indices examined in this project, the SCCCI, a combined index which normalizes for biomass, appeared to be the most appropriate for determining early season cotton leaf $\mathrm{N}$ status. This index utilizes reflectance at three wavelengths, holds a consistent range of values during the application window, and is much less sensitive to plant height and more sensitive to leaf $\mathrm{N}$ concentration than standard NDVI and GNDVI indices. The ability to calculate the SCCI index from some currently produced sensors could allow for rapid adoption for sensor-based $\mathrm{N}$ fertilization. Although other red edge indices showed similar responses to changes in plant height, leaf $\mathrm{N}$ concentration and total $\mathrm{N}$ content, calculation requires reflectance at four wavelengths and indices were slightly less sensitive to crop $\mathrm{N}$ status than SCCCI. The LREI index tends to correlate more strongly with REIP, but it requires an extra wavelength and specified wavelengths do not overlap with commercially produced, active sensors. Therefore, these results warrant further exploration of the simplified SCCCI index as well as other combined indices incorporating reflectance in the red edge for determination of crop leaf $\mathrm{N}$ status as well as total $\mathrm{N}$ content or "biomass $\mathrm{N}$ content."

Acknowledgments Financial support for this project was provided by a Grant from Cotton Incorporated.

Open Access This article is distributed under the terms of the Creative Commons Attribution License which permits any use, distribution, and reproduction in any medium, provided the original author(s) and the source are credited.

\section{References}

Barnes, E.M., Clarke, T.R., Richards, S.E., Colaizzi, P.D., Haberland, J., Kostrzewski, M., Waller, P., Choi, C., Riley, E., Thompson, T., Lascano, R.J., Li, H.,Moran, M.S. (2000). Coincident detection of crop water stress, nitrogen status and canopy density using ground based multispectral data. Unpaginated CD-ROM (13.pdf). In: Robert, P.C., Rust, R.H., Larson, W.E. (Eds.), Proceedings of the 5th International Conference on Precision Agriculture, Bloomington, MN 16-19 July 2000. ASA, CSSA, and SSSA, Madison, WI, USA.

Blackmer, T. M., Schepers, J. S., Varvel, G. E., \& Walter-Shea, E. A. (1996). Nitrogen deficiency detection using reflected shortwave radiation from irrigated corn canopies. Agronomy Journal, 88, 1-5.

Bonham-Carter, G. F. (1988). Numerical procedures and computer program for fitting an inverted Gaussian Model to vegetation and reflectance data. Computers \& Geosciences, 14, 339-356.

Broge, N. H., \& Leblanc, E. (2000). Comparing prediction power and stability of broadband and hyperspectral vegetation indices for estimation of green leaf area index and canopy chlorophyll density. Remote Sensing of Environment, 76, 156-172.

Broge, N. H., \& Mortensen, J. V. (2002). Deriving green crop area index and canopy chlorophyll density of winter wheat from spectral reflectance data. Remote Sensing of Environment, 81, 45-57.

Bronson, K. F., Booker, J. D., Keeling, J. W., Boman, R. K., Wheeler, T. A., Lascano, R. J., et al. (2005). Cotton canopy reflectance at landscape scale as affected by nitrogen fertilization. Agronomy Journal, 97, 654-660.

Buscaglia, H. J., \& Varco, J. J. (2002). Early detection of cotton leaf nitrogen status using leaf reflectance. Journal of Plant Nutrition, 25, 2067-2080.

Cammarano, D., Fitzgerald, G., Basso, B., O’Leary, G., Chen, D., Grace, P., et al. (2011). Use of the canopy chlorophyll content index (CCCI) for remote estimation of wheat nitrogen content in rainfed environments. Agronomy Journal, 103, 1597-1603.

Carter, G. A. (1994). Ratios of leaf reflectances in narrow wavebands as indicators of plant stress. International Journal of Remote Sensing, 15, 697-703. 
Cibula, W. G., \& Carter, G. A. (1992). Identification of a far-red reflectance response to ectomycorrhizae in slash pine. International Journal of Remote Sensing, 13, 925-932.

Clevers, J. G. P. W., De Jong, S. M., Epema, G. F., Addink, E. A., Van Der Meer, F., Bakker, W. H., et al. (2000). MERIS and the Red-Edge Index. In F. van der Meer, A. K. Skidmore, \& W. Bakker (Eds.), Proceedings of the Second EARSeL workshop on imaging spectroscopy (pp. 1-16). Enschede, The Netherlands: EARSeL.

Curran, P. J., Dungan, J. L., \& Gholz, H. L. (1990). Exploring the relationship between reflectance red edge and chlorophyll concentration in slash pine. Tree Physiology, 7, 33-48.

Curran, P. J., Dungan, J. L., Macler, B. A., \& Palmer, S. E. (1991). The effect of a red leaf pigment on the relationship between red edge and chlorophyll concentration. Remote Sensing of Environment, 35, 69-76.

Curran, P. J., Windham, W. R., \& Gholz, H. L. (1995). Exploring the relationship between reflectance red edge and chlorophyll concentration in slash pine leaves. Tree Physiology, 15, 203-206.

Dawson, T. P., \& Curran, P. J. (1998). A new technique for interpolating the reflectance red edge position. International Journal of Remote Sensing, 19, 2133-2139.

Demetriades-Shah, T. H., Steven, M. D., \& Clark, J. A. (1990). High resolution derivative spectra in remote sensing. Remote Sensing of Environment, 33, 55-64.

Eitel, J. U. H., Keefe, R. F., Long, D. S., Davis, A. S., \& Vierling, L. A. (2010). Active ground optical remote sensing for improved monitoring of seedling stress in nurseries. Sensors, 10, 2843-2850.

Eitel, J. H. H., Long, D. S., Gessler, P. E., \& Hunt, E. R. (2008). Combined spectral index to improve ground-based estimates of nitrogen status in dryland wheat. Agronomy Journal, 100, 1694-1702.

Eitel, J. U. H., Long, D. S., Gessler, P. E., \& Smith, A. M. S. (2007). Using in situ measurement to evaluate new RapidEye satellite series for prediction of wheat nitrogen status. International Journal of Remote Sensing, 28, 4183-4190.

El-Shikha, D. M., Barnes, E. M., Clarke, T. R., Hunsaker, D. J., Haberland, J. A., Pinter, P. J, Jr, et al. (2008). Remote sensing of cotton nitrogen status using the Canopy Chlorophyll Content Index (CCCI). Transactions of ASABE., 51, 73-82.

Fitzgerald, G. J., Rodriguez, D., Christensen, L. K., Belford, R., Sadras, V. O., \& Clarke, T. R. (2006). Spectral and thermal sensing for nitrogenand water status in rainfed and irrigated wheat environments. Precision Agriculture, 7, 233-248.

Fridgen, J. L., \& Varco, J. J. (2004). Dependency of cotton leaf nitrogen, chlorophyll, and reflectance on nitrogen and potassium availability. Agronomy Journal, 96, 63-69.

Gates, D. M., Keegan, H. J., Schelter, J. C., \& Weidner, V. R. (1965). Spectral properties of plants. Applied Optics, 4, 11-20.

Gitelson, A. A., Kaufman, Y. J., \& Merzlyak, M. N. (1996). Use of a green channel in remote sensing of global vegetation from EOS-MODIS. Remote Sensing of Environment, 58, 289-298.

Gitelson, A. A., \& Merzlyak, M. N. (1994). Quantitative estimation of chlorophyll using reflectance spectra. Journal of Photochemistry and Photobiology B: Biology, 22, 247-252.

Gitelson, A. A., \& Merzlyak, M. N. (1997). Remote estimation of chlorophyll content in higher plant leaves. International Journal of Remote Sensing, 18, 291-298.

Guyot, G., Baret, F., \& Jacquemoud, S. (1992). Imaging spectroscopy for vegetation studies. In F. Toselli \& J. Bodechtel (Eds.), Imaging spectroscopy: Fundamentals and prospective applications (pp. 145-165). Dordrecht, The Netherlands: Kluwer Academic Publishers.

Haboudane, D., Miller, J. R., Tremblay, P. J., Zarco-Tejada, P. J., \& Dextrazec, L. (2002). Integrated narrow-band vegetation indices for prediction of crop chlorophyll content for application to precision agriculture. Remote Sensing of Environment, 81, 416-426.

Hansen, P. M., \& Schjoerring, J. K. (2003). Reflectance measurement of canopy biomass and nitrogen status in wheat crops using normalized difference vegetation indices and partial least squares regression. Remote Sensing of Environment, 86, 542-553.

Hoque, E., \& Hutzler, P. J. S. (1992). Spectral blue-shift of red edge monitors damage class of beech trees. Remote Sensing of Environment, 39, 81-84.

Horler, D. N. H., Dockray, M., \& Barber, J. (1983a). The red edge of plant leaf reflectance. International Journal of Remote Sensing, 4, 273-288.

Horler, D. N. H., Dockray, M., Barber, J., \& Barrigner, A. R. (1983b). Red edge measurements for remotely sensing plant chlorophyll content. Advances in Space Research, 3, 273-277.

Hunt, E. R., Daughtry, C. S. T., Eitel, J. U. H., \& Long, D. S. (2011). Remote sensing leaf chlorophyll content using a visible band index. Agronomy Journal, 103, 1090-1099.

Lee, Y.-J., Yang, C.-M., Change, K.-W., \& Shen, Y. (2008). A simple spectral index using reflectance of $735 \mathrm{~nm}$ to assess nitrogen status of rice canopy. Agronomy Journal, 100(205), 212. 
Li, H., Lascano, R. J., Barnes, E. M., Booker, J., Wilson, L. T., Bronson, K. F., et al. (2001). Multispectral reflectance of cotton related to plant growth, soil water and texture, and site elevation. Agronomy Journal, 93, 1327-1337.

Masoni, A., Ercoli, L., \& Mariotti, M. (1996). Spectral properties of leaves deficient in iron, sulfur, magnesium, and manganese. Agronomy Journal, 88, 937-943.

Miller, J. R., Hare, E. W., \& Wu, J. (1990). Quantitative characterization of the vegetation red edge reflectance 1. An inverted-Gaussian reflectance model. International Journal of Remote Sensing, 22, $2401-2411$.

Mistele, B., \& Schmidhalter, U. (2008). Estimating the nitrogen nutrition index using spectral canopy reflectance measurements. European Journal of Agronomy, 29, 84-190.

Mistele, B., \& Schmidhalter, U. (2010). Tractor-based quadrilateral spectral reflectance measurements to detect biomass and total aerial nitrogen in winter wheat. Agronomy Journal, 102, 499-506.

Plant, R. E., Munk, D. S., Roberts, B. R., Vargas, R. L., Rains, D. W., Travis, R. L., et al. (2000). Relationships between remotely sensed reflectance data and cotton growth and yield. Transactions of ASAE, 43, 535-546.

$\mathrm{Pu}$, R., Gong, P., Biging, G. S., \& Larrieu, M. R. (2003). Extraction of red edge optical parameters from Hyperion data for estimation of forest leaf area index. IEEE Transactions on Geoscience and Remote Sensing, 41, 916-921.

Raper, T. B., Varco, J. J., \& Hubbard, K. J. (2013). Canopy-based normalized difference vegetation index sensors for monitoring cotton nitrogen status. Agronomy Journal, 105, 1345-1354.

Read, J. J., Tarpley, L., McKinion, J. M., \& Reddy, K. R. (2002). Narrow-waveband reflectance ratios for remote estimation of nitrogen status in cotton. Journal of Environmental Quality, 31, 1442-1452.

Rodriguez, D., Fitzgerald, G. J., Belford, R., \& Christensen, L. K. (2006). Detection of nitrogen deficiency in wheat from spectral reflectance indices and basic crop eco-physiological concepts. Australian Journal of Agricultural Research, 57, 781-789.

Rouse, J.W., Haas, R.H., Schell, J.A., \& Deering, D.W. (1973). Monitoring vegetation systems in the Great Plains with ERTS. Third Earth Resources Technology Satellite-1 Symposium. NASA Sp-351 I, Greenbelt, Maryland, USA pp. 09-317.

Schlemmer, M. R., Francis, D. D., Shanahan, J. F., \& Schepers, J. S. (2005). Remotely measuring chlorophyll content in corn leaves with differing nitrogen levels and relative water content. Agronomy Journal, 97, 106-112.

Shanahan, J. F., Schepers, J. S., Francis, D. D., Varvel, G. E., Willhelm, W. W., Tringe, J. M., et al. (2001). Use of remote-sensing imagery to estimate corn grain yield. Agronomy Journal, 93, 583-589.

Solari, F., Shanahan, J., Ferguson, R., Schepers, J., \& Gitelson, A. (2008). Active sensor relectance measurements of corn nitrogen status and yield potential. Agronomy Journal, 100, 571-579.

Tarpley, L., Reddy, K. R., \& Sassenrath-Cole, G. F. (2000). Reflectance indices with precision and accuracy in predicting cotton leaf nitrogen concentration. Crop Science, 40, 1814-1819.

Thomas, J. R., \& Gausman, H. W. (1977). Leaf reflectance versus leaf chlorophyll and carotenoid concentrations for eight crops. Agronomy Journal, 69, 799-802.

Tucker, C. J. (1979). Red and photographic infrared linear combinations for monitoring vegetation. Remote Sensing of Environment, 8, 127-150.

Vina, A., \& Gitelson, A. A. (2005). New development in the remote estimation of the fraction of absorbed photosynthetically active radiation in crops. Geophysical Research Letters, 32, 1-4.

Zhao, D., Reddy, K. R., Kakani, V. G., Read, J. J., \& Koti, S. (2005). Selection of optimum reflectance ratios for estimating leaf nitrogen and chlorophyll concentrations of field-grown cotton. Agronomy Journal, 97, 89-98. 